\title{
Hypothesis Of Protective Effect Anti Covid - 19 of Iodine And/Or Hydrogen Peroxide Garglings And Mouthwashes To Prevent Infections Through Oral Mucosa
}

\author{
Pierfrancesco Maria Rovere* and Roberto Conedera \\ Free Floating University of Epigenetic Naturology and Applied Research, Italy
}

*Corresponding author: Pierfrancesco Maria Rovere, Free Floating University of Epigenetic Naturology and Applied Research, Italy.

Received Date: June 17, 2020

Published Date: June 29, 2020

\begin{abstract}
Oral cavity mucosa may be a potentially high-risk route of COVID-19 infection. ACE2 (angiotensin-converting enzyme II) receptor on the oral mucosa, which is also the receptor of SARS-CoV and HCoV-NL63, was observed to be highly expressed by the epithelial cells of the tongue [1], therefore oral cavity is a critical site for the study and prevention of COVID-19 infection. The iodine and/or hydrogen peroxide might be helpful in antiviral effect [2] in the context of COVID-19 pandemic [3]. A single oral dose of $130 \mathrm{mg}$ potassium iodide was shown to accumulate in upper airway secretions. Since the virus also affects the eye mucosa, which is also a gateway to Covid 19 , the use of Iodine povidone at $0.5-0.6 \%$, may enhance innate antiviral defenses [4].

Gargling with 3\% hydrogen peroxide (10 vol) [5] 3 times a day and nebulization in the nostrils 2 times a day for 1 minute, but diluted to $50 \%$ because of the nasal mucosa is more delicate, can help [6]. The action should be not only due to the already known oxidizing and mechanical removal properties of hydrogen peroxide correlated to the foam, but also due to the induction of the innate antiviral inflammatory response by overexpression of TLR37, thus reducing the progression of the infection from the upper to the lower respiratory tract [7]. Given the relatively low toxicity and low cost of production, a randomized controlled trial of supplemental iodide would be feasible; iodine and/or hydrogen peroxide mouthwash ang gargling could be a protective device for doctors, nurses and people in contact with covid-19 positive patients.
\end{abstract}

\section{Study}

A particular cell receptor (the angiotensin-converting enzyme II; ACE2), which is the receptor of SARS-CoV and HCoV-NL63, was found to be likely also the cell receptor of the COVID-19 virus. The expression of the ACE2 receptor on the oral mucosa, was observed also on the epithelial cells of the tongue. These findings indicate that the mucosa of oral cavity may be a potentially high-risk route of COVID-19 infection. Studies have shown that mouthwashes and oral gargles with PVP-I-based antiseptics are effective in reduce viral load in the oral cavity and the oropharynx. World Health Organization emphasized the importance of PVP-I by including it in the list of essential medicines. High virucidal activity has been observed against viruses of significant global concern, including hepatitis A and influenza, as well as the Middle-East Respiratory Syndrome and Sudden Acute Respiratory Syndrome coronaviruses. Receptor binding analysis revealed that hemagglutinin inhibition is the likely cause of the PVP-I virucidal activity, rather than the inhibition of host-specific sialic acid receptors. The findings also 
demonstrates two specific mechanisms of reduction of viral growth, namely, PVP-I blockade of viral attachment to the host cell receptors and the inhibition of viral release from infected cells.

Iodide (I-) acts as a protective antioxidant in the body. It is oxidized by the peroxidase/H2O2 system to hypoiodite, which is a potent oxidant for microorganisms. Iodide effectively scavenges reactive oxygen species (ROS) in human blood cells. Fischer, et al. demonstrated the ability of I- to inhibit viral infections by encapsidated and enveloped respiratory virus particles. A single oral dose of $130 \mathrm{mg}$ potassium iodide was shown to accumulate in upper airway secretions. It was suggested that the delivery of I- to the airway mucosa may augment innate antiviral defenses . We suppose that the Covid-19 causes an iodine seizure related to a thyroid apoptotic activation. We think that this process allows the expression of the membrane hemagglutinins; this can trigger the vascular disseminated thrombosis. This enhances a chain reaction which is activated by the inflammation factors favored by the formation of free radicals and by the cytokine storm.

\section{Background}

In the publication Pathology of the thyroid in severe acute respiratory syndrome, it is written that in serum low levels of triiodothyronine and thyroxine, commonly found in patients with SARS, the possibility of thyroid dysfunction raises. The follicular epithelium was found to be damaged with large numbers of cells exfoliated into the follicle. The terminal deoxynucleotidyl transferase-mediated dUPT nick end-labeling (Tunel) [9-15] demonstrated many cells undergoing apoptosis. Follicular architecture was altered and showed distortion, dilatation, and collapse. No distinct calcitonin-positive cells were detectable in the SARS thyroids. In conclusion, both parafollicular and follicular cells were found injured [16-19].

This may provide an explanation both for low serum triiodothyronine and thyroxine levels and the osteonecrosis of the femoral head associated with patients with SARS [20-23]. Apoptosis may play a role in the pathogenesis of SARS associated coronavirus infection in the thyroid gland [24-27]. Overproduction of IL- 6 reduces thyroid performance by decreasing the conversion from T4 to T3, resulting in lower T3 levels. This occurs because IL-6 causes oxidative stress and reduces glutathione levels [28-30].

\section{Iodine and Hemo-Agglutinins}

We must consider that one of the characteristic symptoms of coronavirus is asthenia, attributable to a possible thyroid involvement [31-33]. We know that iodine has a correlation with hemagglutinins and that SARS CoV-2 explodes with disseminated vasal thrombosis $[34,35]$. Surely there must be a correlation between the two events [36-38]. The disease could evolve in two steps: the first induces iodine consumption and thyroid deactivation to prepare the ground for a subsequent explosion phase of the disseminated vascular thrombosis which can no more be controlled by iodine. If this were the case, iodine supplementation would find a protective indication for the second stage of the virus attack. Research requires monitoring of thyroid function that can be easily investigated on patients screening, which could provide new investigative hypothesis to found new resources to protect the organism from the collapse found in those affected by the disease [39-42].

\section{Conclusion}

With recent immunological acquisitions we know that iodine has a powerful antiviral action with an anti-hemagglutin-genic effect. The possibility of providing iodine oral supplements to compensate for a possible thyroid dysfunction and iodine-related disorders, both pre-existing and caused by the Sars Cov-2 virus, is envisaged. To help prevent infections, take $130 \mathrm{mg}$ potassium iodide that was shown to accumulate in upper airway secretions. To protect the eye mucosa, which is also a gateway to Covid 19, the use of Iodine povidone at $0.5-0.6 \%$ may augment innate antiviral defenses. To protect the oral cavity, gargling with $3 \%$ hydrogen peroxide (1o vol) without swallowing, 3 times a day, and nebulization in the nostrils 2 times a day for 1 minute, diluted to $50 \%$ because of the nasal mucosa is more delicate. Given the relatively low toxicity and low cost, a randomized controlled trial of supplemental iodide would be feasible: iodine and/or hydrogen peroxide mouthwash and gargling when there is a risk of viral infection, could be a protective device for doctors, nurses and people in contact with Covid positive patients. We can also consider the protective effect of iodine against radioactive particles, following the fires in Chernobyl and the human production. We must consider that we have an increased rate of thyroid cancer, which affects also more and more young people due to the presence of radioactive particles and radioactive Iodine in the air; we can suppose that there may even be a pathological strengthening between virus and radiation. Iodine can have a double protective effect: antiviral and anti radioactive on the thyroid.

\section{Acknowledgement}

None.

\section{Conflict of Interest}

No conflict of interest.

\section{References}

1. Luiz Meirelles (2020) Oral Mucosa Shows High Expression of ACE2 Receptor of 2019-nCoV.

2. Maren Eggers (2019) Infectious Disease Management and Control with Povidone Iodine. Infectious Diseases and Therapy 8: 581-593.

3. Fischer AJ, Lennemann NJ, Krishnamurthy S, Péter Pócza, Lakshmi Durairaj, et al. (2011) Enhancement of Respiratory Mucosal Antiviral Defenses by the Oxidation of Iodide. Am J Respir Cell Mol Biol 45(4): 874-881.

4. Mika Turkia (2020) COVID-19 and iodide.

5. Caruso A, Del Prete A, Lazzarino A, Capaldi R, Grumetto L (2020) May hydrogen peroxide reduce the hospitalization rate and complications of SARS-CoV-2 infection. Infect Control Hosp Epidemiol pp. 1-2. 
6. Salvatore Spagnolo (2020) Covid-19 as a Cause of Pneumonia and Diffuse Peripheral Pulmonary Embolism. Early Anticoagulant Treatment to Prevent Thrombi Formation.

7. Maren Eggers (2019) Infectious Disease Management and Control with Povidone Iodine. Infect Dis Ther 8(4): 581-593.

8. Maren Eggers (2020) Labor Prof Gisela Enders MVZ GbR, Stuttgart, Germany.

9. Lan Wei, Shen Sun, Cai-Hong Xu, Jing Zhang, Yun Xu, et al. (2007) Pathology of the thyroid in severe acute respiratory syndrome. Hum Pathol 38(1): 95-102.

10. Eggers M, Eickmann M, Kowalski K, Juergen Zorn, Karen Reimer, et al. (2015) Povidone-iodine hand wash and hand rub products demonstrated excellent in vitro virucidal efficacy against Ebola virus and modified vaccinia virus Ankara, the new European test virus for enveloped viruses. BMC Infect Dis 15: 375.

11. Eggers M, Koburger-Janssen T, Ward LS, Newby C, Müller S (2018) Bactericidal and virucidal activity of Povidone-Iodine and chlorhexidine gluconate cleansers in an in vivo hand hygiene clinical simulation study. Infect Dis Ther 7(2): 235-247.

12. Herruzo R, Vizcaino MJ, Yela R (2018) Surgical hand preparation with chlorhexidine soap or povidone iodine: new methods to increase immediate and residual effectiveness, and provide a safe alternative to alcohol solutions. J Hosp Infect 98(4): 365-368.

13. Schreier H, Erdos G, Reimer K, B König, W König, et al. (1997) Molecular effects of povidone-iodine on relevant microorganisms: an electronmicroscopic and biochemical study. Dermatology. 195(Suppl 2): 111116.

14. Mayer S, Boos M, Beyer A, Fluit AC, Schmitz FJ (2001) Distribution of the antiseptic resistance genes qacA, qacB and qacC in 497 methicillin resistant and -susceptible European isolates of Staphylococcus aureus. J Antimicrob Chemother 47(6): 896-897.

15. Skurray RA, Rouch DA, Lyon BR, MT Gillespie, JM Tennent, et al. (1998) Multiresistant Staphylococcus aureus: genetics and evolution of epidemic Australian strains. J Antimicrob Chemother 21(Suppl C): 19 39.

16. Coia JE, Duckworth GJ, Edwards DI, M Farrington, C Fry, et al. (2006) Guidelines for the control and prevention of meticillin-resistant Staphylococcus aureus (MRSA) in healthcare facilities. J Hosp Infect 63S: S1-S44

17. Kunisada T, Yamada K, Oda S, Hara O (1997) Investigation on the efficacy of povidone-iodine against antiseptic-resistant species. Dermatology 195(Suppl 2): 14-18.

18. Houang ET, Gilmore OJA, Reid C, EJ Shaw (1976) Absence of bacterial resistance to povidone iodine. J Clin Pathol 29: 752-754.

19. Wand ME, Bock LJ, Bonney LC, Sutton JM (2017) Mechanisms of increased resistance to chlorhexidine and cross-resistance to colistin following exposure of Klebsiella pneumoniae clinical isolates to chlorhexidine. Antimicrob Agents Chemother 61(1): e01162-16.

20. Boyce JM, Pittet D (2002) Guideline for hand hygiene in health-care settings: recommendations of the Healthcare Infection Control Practices Advisory Committee and the HICPAC/SHEA/APIC/IDSA Hand Hygiene Task Force. Morbid Mortal Wkly Rep 51(RR-16): 1-45.

21. Eggers M, Koburger-Janssen T, Eickmann M, Zorn J (2018) In vitro bactericidal and virucidal efficacy of Povidone-Iodine gargle/mouthwash against respiratory and oral tract pathogens. Infect Dis Ther 7: 249-259.

22. (2014) World Health Organization. Influenza (seasonal).

23. Sriwilaijaroen N, Wilairat P, Hiramatsu H, Tadanobu Takahashi, Takash Suzuki, et al. (2009) Mechanisms of the action of povidone-iodine against human and avian influenza A viruses: its effects on hemagglutination and sialidase activities. Virol J 6: 124

24. Kawana R, Kitamurd T, Nakagomi O, I Matsumoto, M Arita, et al. (1997) Inactivation of human viruses by Povidone-lodine in comparison with other antiseptics. Dermatology 195(suppl2): 29-35.

25. Ogata Junichi, Minami Kouichiro, Miyamoto Hiroshi, Horishita Takafumi, Ogawa Midori, et al. (2014) Gargling with povidone-iodine reduces the transport of bacteria during oral intubation. Can J Anesth 51(9): 932936.

26. Edwards R, Harding KG (2004) Bacteria and wound healing. Curr Opin Infect Dis 17: 91-96.

27. Paddle-Ledinek JE, Nasa Z, Cleland HJ (2006) Effect of different wound dressings on cell viability and proliferation. Plast Reconstr Surg 117: 110S-118S

28. Boyce ST, Warden GD, Holder IA (1995) Cytotoxicity testing of topical antimicrobial agents on human keratinocytes and fibroblasts for cultured skin grafts. J Burn Care Rehabil 16: 97-103.

29. Welch D, Buonanno M, Grilj V, Shuryak I, Crickmore C, et al. (2018) Far-UVC light: a new tool to control the spread of airborne-mediated microbial diseases. Sci Rep 8: 2752.

30. Larson E (1995) APIC Guideline for handwashing and hand antisepsis in health care settings. Am J Infect Control 4: 251-269.

31. Niedner R (1997) Cytotoxicity and sensitization of povidone-iodine and other frequently used anti-infective agents. Dermatology 195(suppl2): 89-92.

32. Steinmann J, Paulmann D, Becker B, Bischoff B, Steinmann E, et al. (2012) Comparison of virucidal activity of alcohol-based hand sanitizers versus antimicrobial hand soaps in vitro and in vivo. J Hosp Infect 82: 277-280.

33. Eggers M, Koburger-Janssen T, Ward LS, Newby C, Muller S (2018) Bactericidal and virucidal activity of povidone-iodine and chlorhexidine gluconate cleansers in an in vivo hand hygiene clinical simulation study. Infect Dis Ther 7(2): 235-247

34. Larson EL (1995) APIC guidelines for handwashing and hand antisepsis in health care settings. Am J Infect Control 23(4): 251-269.

35. Lachapelle JM, Castel O, Casado AF, Leroy B, Micali G, et al. (2013) Antiseptics in the era of bacterial resistance: a focus on povidone iodine. Clin Pract 10(5): 579.

36. Nagatake T, Ahmed K, Oishi K (2002) Prevention of respiratory infections by povidone-iodine gargle. Dermatology 204(suppl1): 32-36

37. Shiraishi T, Nakagawa Y (2002) Evaluation of the bactericidal activity of povidone-iodine and commercially available gargle preparations. Dermatology 204(suppl 1): 37-41.

38. Kramer A, Dissemond J, Kim S, Willy C, Mayer D, et al. (2018) Consensus on wound antisepsis: update 2018. Skin Pharmacol Physiol 31(1): 2858.

39. Cherniack EP (2010) Bugs as drugs, Part 1: insects: the" new" alternative medicine for the 21st century. Altern Med Rev 15(2): 124-135.

40. Nobukuni K, Hayakawa N, Namba R, Ihara Y, Sato K, et al. (1997) The influence of long-term treatment with povidone-iodine on thyroid function. Dermatology 195(Suppl. 2): 69-72.

41. Cortelyou PR (1968) Use of peroxide of hydrogen in diseases of the throat and nose. J Med Assoc Ga 57(9): 449-450.

42. Method for detecting DNA fragmentation by labeling the $3^{\prime}$ - hydroxyl termini in the double-strand DNA breaks generated during apoptosis. 